Article

\title{
Estimation of High-Resolution Surface Shortwave Radiative Fluxes Using SARA AOD over the Southern Great Plains
}

\author{
Eslam Javadnia 1,2,*, Ali Akbar Abkar ${ }^{1,3}$ and Per Schubert 4,* \\ 1 Department of Photogrammetry and Remote Sensing, Faculty of Geodesy \& Geomatics Engineering, \\ K. N. Toosi University of Technology, Tehran 19967-15433, Iran; abkar@kntu.ac.ir \\ 2 Surveying Engineering Department, Faculty of Engineering, University of Zanjan, Zanjan 45371-38791, Iran \\ 3 AgriWatch B.V., Weerninklanden 24, 7542 SC Enschede, The Netherlands \\ 4 Department Science, Environment and Society, Faculty of Education and Society, Malmö University, \\ 20506 Malmö, Sweden \\ * Correspondence: jjavadnia@mail.kntu.ac.ir (E.J.); per.schubert@mah.se (P.S.); \\ Tel.: +46-40-6658652 (P.S.); Fax: +46-40-6657573 (P.S.)
}

Academic Editors: Dongdong Wang, Alfredo R. Huete and Prasad S. Thenkabail

Received: 29 August 2017; Accepted: 2 November 2017; Published: 8 November 2017

\begin{abstract}
Atmospheric aerosol optical depth (AOD) plays a determinant role in estimations of surface shortwave (SW) radiative fluxes. Therefore, this study aims to develop a hybrid scheme to produce surface SW fluxes, based on AOD at 1-km spatial resolution retrieved from the Simplified Aerosol Retrieval Algorithm (SARA) and several Terra MODIS land and atmospheric products (i.e., geolocation properties, water vapor amount, total ozone column, surface reflectance, and top-of-atmosphere (TOA) radiance). Estimations based on SARA were made over the Southern Great Plains (SGP) under cloud-free conditions in 2014 and compared with estimations based on the latest Terra MODIS AOD product at 3-km resolution. Validation against ground-based measurements showed that SARA-based fluxes obtain lower RMSE and bias values compared with MODIS-based estimations. MODIS-based downward and net fluxes are satisfactory, while the direct and diffuse components are less reliable. The results demonstrate that the SARA-based scheme produces better surface SW radiative fluxes than the MODIS-based estimates provided in this and other similar studies and that these fluxes are comparable to existing CERES data products which have been tested over the SGP.
\end{abstract}

Keywords: shortwave radiative fluxes; MODIS; AOD; SARA; Southern Great Plains

\section{Introduction}

The main part of downward radiative fluxes reaching the Earth's surface is in the range of the shortwave (SW) spectrum and consists of two components: direct and diffuse fluxes. The net SW radiative flux, defined as the difference between the downward and upward fluxes at the Earth's surface, controls the total energy exchange between the atmosphere and land/ocean surface, and significantly affects climatic forming and change [1,2]. SW fluxes are involved in many processes such as evaporation, photosynthesis, and heating of soil and water [3,4], as well as key indicators of drought [5]. The direct component is an important factor for identifying the best locations for solar energy systems that focus on concentrating photovoltaics/solar thermal technology.

Many algorithms have been developed to estimate SW radiative fluxes at the Earth's surface based on various remote sensing data [6-18]. The methods used to develop these algorithms can be grouped into two classes: empirical methods and theoretical methods. The empirical methods establish regressions by directly linking satellite radiance data and ground-measured radiative fluxes. 
Although they are simple to run, the results are site-specific and cannot be extrapolated over other regions. The theoretical methods establish parameterized schemes to simulate the direct interaction between solar radiation and the atmosphere, including absorption by water vapor, gas, and ozone, as well as absorption and scattering by aerosols. Several theoretical methods for estimating SW radiation components are based on remote-sensing data, particularly on MODerate-resolution Imaging Spectroradiometer (MODIS) data products. The main reason for this is that remote sensing provides many standardized land and atmospheric products such as aerosol optical depth (AOD), water vapor amount, total ozone column, and albedo at 1-10-km spatial resolutions.

Aerosol optical depth (AOD) is known to be a critical input to estimations of SW radiative fluxes under cloud-free conditions, particularly the direct component that is highly sensitive to AOD. Recent studies have shown that the accuracy of existing solar radiation maps is not always satisfactory $[19,20]$, and it has been found that a large part of these uncertainties could be explained by inaccurate aerosol data used to model solar radiation for cloud-free conditions [21,22]. To date, most researchers employ the level-3 MODIS AOD product (MOD08), which is a global daily spatial aggregation of the level 2 product (10-km spatial resolution) into a regular grid with a spatial resolution of $1^{\circ}$ [23], and this may not be suitable for radiative applications at scales between 1 and $10 \mathrm{~km} \mathrm{[6].}$ Recent land surface and climate models require a 10-km or finer spatial resolution [24-26].

The current operational MODIS AOD product over land is known as Collection 6 (C6), which replaces Collection 5 (C5) and is based on two algorithms, namely the Dark Target (DT) $[27,28]$ and Deep Blue (DB) [29] algorithms. As MODIS DT and DB algorithms at 10-km resolution were unable to resolve local aerosol gradients and city level features, a global DT AOD product at a nominal resolution of 3 km (MOD04_3K) [30] was introduced in the operational C6 AOD product. This is in addition to the DT and DB AOD products at the standard 10-km resolution. Generally, DT algorithms overestimate AOD over bright surfaces and underestimate AOD over unusually dark surfaces under clear atmospheric conditions [27]. Furthermore, it is unable to estimate the AOD under turbid conditions, due to its limitation of DT selection criteria, thus producing many missing pixels. The above-mentioned problems would affect estimations and make it difficult to obtain SW fluxes at $1-\mathrm{km}$ spatial resolution. Therefore, a more effective satellite aerosol retrieval with higher resolution should be integrated in estimations of SW fluxes. This study integrates the effective Simplified Aerosol Retrieval Algorithm (SARA), developed by Bilal [31], with the simplified radiative transfer model, developed by Yang et al. [32], using various MODIS land and atmospheric products to estimate SW radiative fluxes at the nominal resolution of $1 \mathrm{~km}$.

The aim of this paper is to propose an effective scheme for estimation of instantaneous SW radiative fluxes at high spatial resolution: A hybrid scheme was developed by combining Yang et al.'s simplified radiative transfer model with SARA and MODIS land and atmospheric products (hereafter called the SARA-based scheme). Likewise, the simplified radiative transfer model was combined with the latest MODIS 3-km aerosol product (MOD04_3K) and other MODIS land and atmospheric products (hereafter called MODIS-based scheme). The schemes were then used to estimate fluxes over the Southern Great Plains (SGP) region under cloud-free conditions in 2014 and were evaluated and compared by validating estimated fluxes against ground-based measurements.

\section{Materials and Methods}

\subsection{Study Area and Data}

The Atmospheric Radiation Measurement (ARM) program, funded by U.S. Department of Energy, maintains continuous measurements of various meteorological and surface variables within the SGP. The SGP covers a large part of the central United States, including most of the state of Oklahoma and the southern part of Kansas. The study area ranges in latitude from about $35.5^{\circ} \mathrm{N}-37.5^{\circ} \mathrm{N}$ and in longitude from about $95.5^{\circ} \mathrm{W}-99.5^{\circ} \mathrm{W}$ (The red box in Figure 1). In this study, data from 13 solar infrared radiation stations (SIRS) at the SGP extended facilities (EF) were used for validation purposes. 
They provide continuous measurements of downwelling and upwelling SW radiative fluxes [33]. The direct and diffuse components of downwelling SW radiation are measured with normal incidence pyrheliometers (NIP) and precision spectral pyranometers (PSP), respectively, while upwelling SW radiation is measured by the PSP. All radiometers are manufactured by The Eppley Laboratory, Inc., Newport, RI, USA. The 1-min SIRS data, along with details about the instruments, are available from the ARM web site [34] . The measurement data from SGP are aggregated to a 15-min interval when comparing with the estimates of SW radiative fluxes presented in Section 2.3.

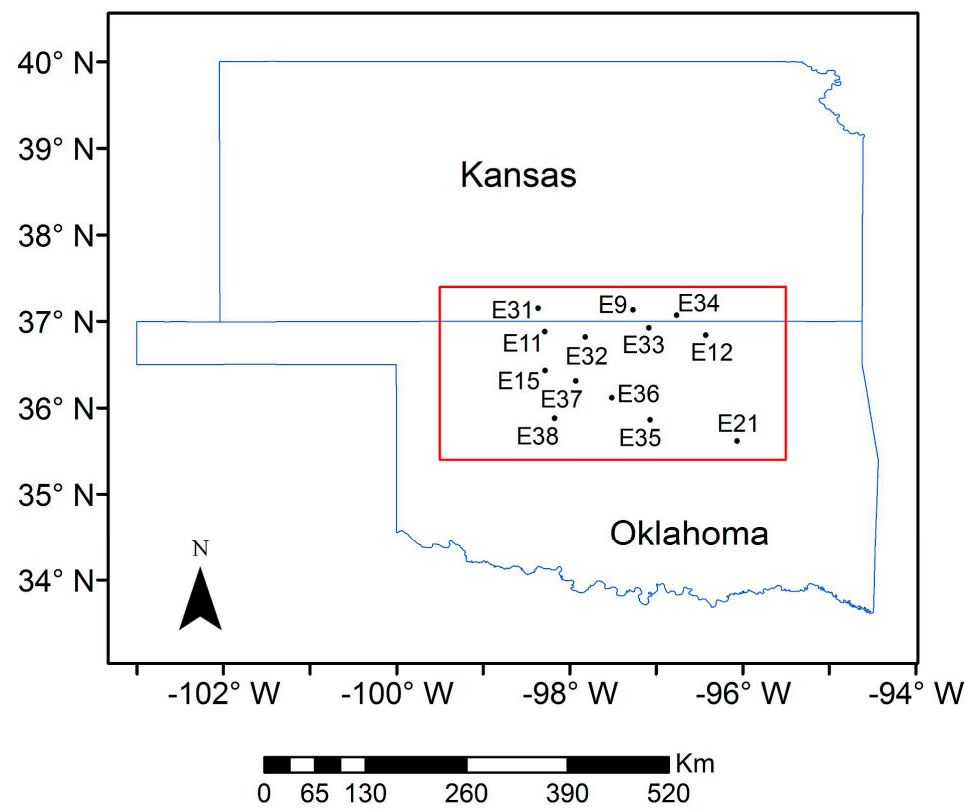

Figure 1. Atmospheric radiation measurement (ARM) ground sites within the Southern Great Plains (SGP) in Oklahoma and Kansas. The red box shows the SGP domain for this study.

\subsection{MODIS Data and Study Days}

Terra-MODIS atmospheric and land products at levels 1, 2, and 3 are required to estimate SARA- and MODIS-based SW radiative fluxes for cloud-free days. The geolocation properties, including height, solar and sensor angles (zenith and azimuth), and top-of-atmosphere (TOA) radiance at green wavelength are obtained from level $1 \mathrm{~A}$ and level 1B products, respectively. Surface reflectance at green wavelength, land surface temperature (LST), water vapor amount, total ozone column, and AOD are extracted from the level 2 (L2) land and atmospheric products. Black-sky albedo and white-sky albedo are taken from the level 3 (L3) albedo product. The various MODIS data products and parameters used in the SARA- and MODIS-based schemes, along with their spatial resolutions, are summarized in Table 1. The schemes were run at the resolution of $1 \mathrm{~km}$. However, even if the estimated SW fluxes are at the $1-\mathrm{km}$ resolution, the input data are only at the nominal resolutions of 1,3, and 5-km. The $\mathrm{L} 2$ aerosol and atmospheric profile products have $5 \mathrm{~km}$ and $3 \mathrm{~km}$ resolutions, respectively and, therefore, both were resampled to $1 \mathrm{~km}$.

Twenty-six cloud-free days in the year 2014 were selected in terms of the LST product with less than $20 \%$ cloud cover relative to the entire scene (Table 2). The LST data product is available for only cloud-free pixels, thus counting the number of pixels in LST for which land surface temperature was available served as an indicator of the cloud cover over the study site. 
Table 1. Summary of the MODIS data products used in this study.

\begin{tabular}{|c|c|c|c|c|c|}
\hline MODIS Product & Short Name & Resolution & Parameters Used & $\begin{array}{l}\text { MODIS-Based } \\
\text { Scheme }\end{array}$ & $\begin{array}{l}\text { SARA-Based } \\
\text { Scheme }\end{array}$ \\
\hline $\begin{array}{l}\text { Land Surface } \\
\text { Temperature }\end{array}$ & MOD11 & $1-\mathrm{km}$ & Surface temperature & $\checkmark$ & $\checkmark$ \\
\hline Level-1B Radiance & MOD02 & $1-\mathrm{km}$ & $\begin{array}{l}\text { Top of Atmosphere } \\
\text { radiance band } 4\end{array}$ & & $\checkmark$ \\
\hline $\begin{array}{c}\text { Geolocation properties } \\
\text { Product }\end{array}$ & MOD03 & $1-\mathrm{km}$ & $\begin{array}{c}\text { Height } \\
\text { Solar zenith angle } \\
\text { Sensor zenith angle } \\
\text { Solar azimuth angle } \\
\text { Sensor azimuth angle }\end{array}$ & $\checkmark$ & $\begin{array}{l}\checkmark \\
\checkmark \\
\checkmark \\
\checkmark \\
\checkmark\end{array}$ \\
\hline Aerosol Product & MOD04-3K & $3-\mathrm{km}$ & Aerosol optical depth & $\checkmark$ & \\
\hline Perceptible Water Product & MOD05 & $1-\mathrm{km}$ & Water vapor amount & $\checkmark$ & $\checkmark$ \\
\hline Atmospheric Profile & MOD07 & $5-\mathrm{km}$ & Total ozone column & $\checkmark$ & $\checkmark$ \\
\hline $\begin{array}{l}\text { Level-2 Land Surface } \\
\text { Reflectance }\end{array}$ & MOD09 & $1-\mathrm{km}$ & Surface reflectance band 4 & & $\checkmark$ \\
\hline Albedo Product & MCD43B3 & $1-\mathrm{km}$ & $\begin{array}{l}\text { Black-sky albedo } \\
\text { white-sky albedo }\end{array}$ & $\checkmark$ & $\checkmark$ \\
\hline
\end{tabular}

Table 2. Acceptable cloud-free days (i.e., $80 \%$ or more of the study site had no cloud cover) for the MODIS onboard the Terra satellite for the Southern Great Plains (SGP) during 2014.

\begin{tabular}{cc}
\hline Months (Number of Acceptable Cloud-Free Days) & Julian Days \\
\hline January (3) & $16,18,19$ \\
February (2) & 48,58 \\
March (4) & $71,78,79,90$ \\
April (4) & $94,99,105,112$ \\
May (1) & 122 \\
July (2) & 192,201 \\
August (2) & 224,235 \\
September (2) & 247,250 \\
October (3) & $280,303,304$ \\
November (3) & $310,323,329$ \\
\hline
\end{tabular}

\subsection{Retrieval of SW Radiative Fluxes}

\subsubsection{Instantaneous Downward and Net SW Radiative Fluxes}

The downward SW radiative flux reaching the Earth's surface, commonly named surface irradiance and noted as I hereafter, can be expressed as:

$$
I=I_{0} \mu_{s} T
$$

where $I_{0}$ is the TOA irradiance and is calculated from the solar constant, $I_{s c}$, and the day number, $d_{n}$, as follows:

$$
I_{0}=I_{s c}\left(1+0.033 \cos \left(2 \pi d_{n} / 365\right)\right)
$$

$T$ is the atmospheric shortwave transmittance that accounts for atmospheric effects.

In this study, the variable of $T$ is derived from MODIS data. $T$ can be influenced by a number of extinction (scattering and absorption) processes in the atmosphere, including permanent gas absorption, Rayleigh scattering, ozone absorption, water vapor absorption, and aerosol extinction [35,36], leading to the partitioning of the TOA irradiance into direct and diffuse radiations. The corresponding spectral radiative transmittance factors are represented by $\tau_{g}, \tau_{r}, \tau_{w}, \tau_{o z}$, and $\tau_{a}$, which are used to calculate the broadband radiative transmittance of the atmosphere, described by 
two functions: the solar direct beam radiative transmittance $\left(T_{b}\right)$ and the solar diffuse radiative transmittance $\left(T_{d}\right)$. The parameterizations of these transmittances have been comprehensively discussed in various studies. This study uses the broadband model of Yang et al. [32] to compute the broadband transmittance functions by spectral radiative transmittance factors for cloud-free conditions. Performance of this model has been accurately evaluated in several studies [37-39]. The direct beam irradiance $\left(I_{b}\right)$, diffuse irradiance $\left(I_{d}\right)$ that is expressed as the difference between the direct irradiance and a fictitious beam subject only to molecular absorption, and then global irradiance $\left(I_{g}\right)$ can be calculated using the broadband transmittance functions as follows:

$$
\begin{aligned}
& I_{b}=I_{0} \mu_{s} T_{b} \\
& I_{d}=I_{0} \mu_{s} T_{d} \\
& I_{g}=I_{b}+I_{d}
\end{aligned}
$$

Net surface SW radiative flux $\left(I_{n}\right)$ depends on accurate estimation of the global irradiance and surface albedo. The surface albedo can be calculated using an equation presented in Moody et al. [40] and black and white-sky albedos derived from the MODIS albedo product. Therefore, $I_{n}$ can be expressed as a function of the surface albedo $(\alpha)$ and irradiance $\left(I_{g}\right)$ as follows:

$$
I_{n}=I_{g}(1-\alpha)
$$

Estimations of the broadband transmittance functions in Equations (3)-(5) require the spectral radiative transmittance factors of the atmospheric compositions: $\tau_{g}, \tau_{r}, \tau_{w}, \tau_{o z}, \tau_{a}$, which can be calculated as follows:

$$
\begin{gathered}
\tau_{g}=\exp \left(-0.0117 m_{c}^{0.3139}\right) \\
\tau_{r}=\exp \left[-0.00873517 m_{c}\left(0.547+0.014 m_{c}-0.00038 m_{c}^{2}+4.6 \times 10^{-6} m_{c}^{3}\right)^{-4.08}\right] \\
\tau_{w}=\min [1.0,0.909-0.036 \ln (m w)] \\
\tau_{o z}=\exp \left[-0.0365(m l)^{0.7136}\right] \\
\tau_{a}=\exp \left\{-m \beta\left[0.6777+0.1464(m \beta)-0.00626(m \beta)^{2}\right]^{-1.3}\right\}
\end{gathered}
$$

$w, l$, and $\beta$ are the thickness of the ozone layer, the precipitable water, and the Ångström turbidity coefficient $(0.406 \times$ AOD), respectively. In addition, the air mass $(m)$ and the pressure-corrected air mass $\left(m_{c}\right)$ are calculated from Equations (12) and (13):

$$
\begin{gathered}
m=\left(\cos \theta+0.15(\theta+3.885)^{-1.253}\right)^{-1} \\
m_{c}=m p / p_{0}
\end{gathered}
$$

$\theta$ is the SZA, $p$ is the air pressure, $p_{0}$ is the air pressure at sea level $(1013 \mathrm{hPa})$. Then, the broadband transmittance functions, i.e., the direct transmittance $\left(T_{b}\right)$, the diffuse transmittance $\left(T_{d}\right)$, and the global transmittance $(T)$, are calculated as follows:

$$
\begin{gathered}
T_{b}=\tau_{o z} \tau_{w} \tau_{g} \tau_{r} \tau_{a}-0.013 \\
T_{d}=0.5\left[\tau_{o z} \tau_{g} \tau_{w}\left(1-\tau_{r} \tau_{a}\right)+0.013\right] \\
T=T_{b}+T_{d}
\end{gathered}
$$

A sensitivity study and a detailed error analysis in Gueymard [38] revealed that the predicted surface irradiance is very sensitive to errors in the turbidity and increases sharply with air mass. The methods for retrieving irradiance from remote sensing data commonly employ MODIS standard 
aerosol products. In addition to the MODIS aerosol retrieval algorithm, many algorithms have been developed to retrieve AOD from satellite data. In this study, in order to integrate the impact of aerosols in the estimation of SW radiative fluxes, AOD is retrieved by employing Bilal's [31] new algorithm, SARA, using both MODIS data and ground observations.

\subsubsection{Retrieval of SARA AOD}

SARA (Equation (17)) was used to retrieve AOD from MODIS data products at 1-km spatial resolution. It is based on real viewing geometry and is encompassing a wide range of aerosol conditions and types [34,35]. SARA also has three assumptions: (1) the surface is Lambertian; (2) single scattering approximation; and (3) the single scattering albedo (SSA) and the asymmetry parameter (AP) do not vary spatially over the region on the day of retrieval [34]. Strong performances of this algorithm, compared to MODIS AOD, were verified under low and high aerosol loading in Bilal's studies [31,41-43]. SARA is expressed as follows:

$$
\begin{aligned}
\tau_{a, \lambda}=\frac{4 \mu_{s} \mu_{v}}{\omega_{0} P_{a\left(\theta_{s}, \theta_{v}, \phi\right)}} & {\left[\rho_{\operatorname{TOA}\left(\lambda, \theta_{s}, \theta_{v}, \phi\right)}-\rho_{R a y}\left(\lambda, \theta_{s}, \theta_{v}, \phi\right)\right.} \\
& \left.-\frac{e^{-\left(\tau_{R}+\tau_{a, \lambda}\right) / \mu_{s}} e^{-\left(\tau_{R}+\tau_{a, \lambda}\right) / \mu_{v}} \rho_{s\left(\lambda, \theta_{s}, \theta_{v}, \phi\right)}}{1-\rho_{s\left(\lambda, \theta_{s}, \theta_{v}, \phi\right)}\left(0.92 \tau_{R}+(1-g) \tau_{a, \lambda}\right) \exp \left[-\left(\tau_{R}+\tau_{a, \lambda}\right)\right]}\right]
\end{aligned}
$$

where $\tau_{a, \lambda}=$ spectral AOD, $\tau_{R}=$ Rayleigh optical depth, $\rho_{T O A}=$ TOA reflectance, $\rho_{s}=$ surface reflectance, $\rho_{\text {Ray }}=$ Rayleigh reflectance, $P_{a}=$ aerosol phase function, $\omega_{0}=$ single scattering albedo, $g=$ asymmetry parameter, $\mu_{s}=$ cosine of SZA, $\mu_{v}=$ cosine of sensor zenith angle, $\theta_{s}=\mathrm{SZA}, \theta_{v}=$ view zenith angle, $\phi=$ relative azimuth angle, and $\lambda=$ wavelength (here $\lambda=550 \mathrm{~nm}$, the green wavelength of MODIS).

The SARA algorithm requires AErosol RObotic NETwork (AERONET) data to retrieve the $\omega_{0}$ and $g$ over the whole study region. In this study, level 2.0 Version 2 AOD data (cloud-screened and quality-assured) from the AERONET site "CART", which is located on the center of the SGP, were obtained to determine $\omega_{0}$ and $g$. Daily values of $\omega_{0}$ and $g$ for all study days were determined by matching SARA AOD as a function of $\omega_{0}$ and $g$, and the averaged AOD from the AERONET site, within \pm 30 min of the Terra satellite local overpass time. Then, $\omega_{0}$ and $g$, together with the MODIS TOA radiance and surface reflectance at green wavelength and solar and sensor angles (zenith and azimuth), were used to retrieve 1-km AOD over the study sites at Terra satellite overpass time. The retrieved SARA AOD was then extracted and averaged for $3 \mathrm{~km} \times 3 \mathrm{~km}$ spatial subsets, centered on the respective SGP sites [44]. For equations and detailed computation procedures, see Bilal [31].

The Ångstrom turbidity coefficient was derived from AOD using the following procedure, which has been investigated widely. AOD is wavelength-dependent:

$$
\tau_{a, \lambda}=\beta \lambda^{-\alpha}
$$

where $\lambda(\mu \mathrm{m})$ is the wavelength, $\tau_{a, \lambda}$ is the AOD value, $\beta$ is the Angstrom turbidity coefficient, and $\alpha$ is the Ångstrom exponent. In the Yang model (see Leckner [45]), the Ångstrom turbidity coefficient is defined at wavelength $\lambda=0.5 \mu \mathrm{m}$ with Ångstrom exponent $\alpha=1.3$. That is:

$$
\beta=0.5^{1.3} \tau_{0.5}=0.406 \times \mathrm{AOD}
$$

\subsubsection{SW Radiative Fluxes from SARA AOD and MODIS Data}

The SARA- and MODIS-based schemes used to compute the SW radiative fluxes are described in Figure 2. In order to estimate SARA-based SW radiative fluxes, the following steps were taken: Firstly, SARA AOD was retrieved from the AERONET single scattering albedo and asymmetry parameter together with MODIS geolocation properties, TOA radiance, and surface reflectance at green wavelengths. Secondly, the transmittance due to aerosol extinction was calculated from SARA AOD while transmittances due to water vapor and ozone absorption were calculated from MODIS 
water vapor amount and total ozone column products, respectively. Transmittance due to Rayleigh scattering and permanent gas absorption was also calculated from MODIS SZA. Then, global, direct, and diffuse irradiances were estimated for cloud-free pixels.

In order to estimate MODIS-based SW radiative fluxes, the following steps were taken: Firstly, in addition to the calculation of transmittance factors from MODIS data (shaded area in Figure 2), transmittance due to aerosol extinction was calculated from the MODIS 3-km AOD product. Then, global, direct, and diffuse irradiances were estimated for cloud-free pixels.

Finally, the blue sky was derived using the MODIS black and white-sky albedos, and then combined with the SARA- and MODIS-based global irradiances, resulting in net SW radiative fluxes.

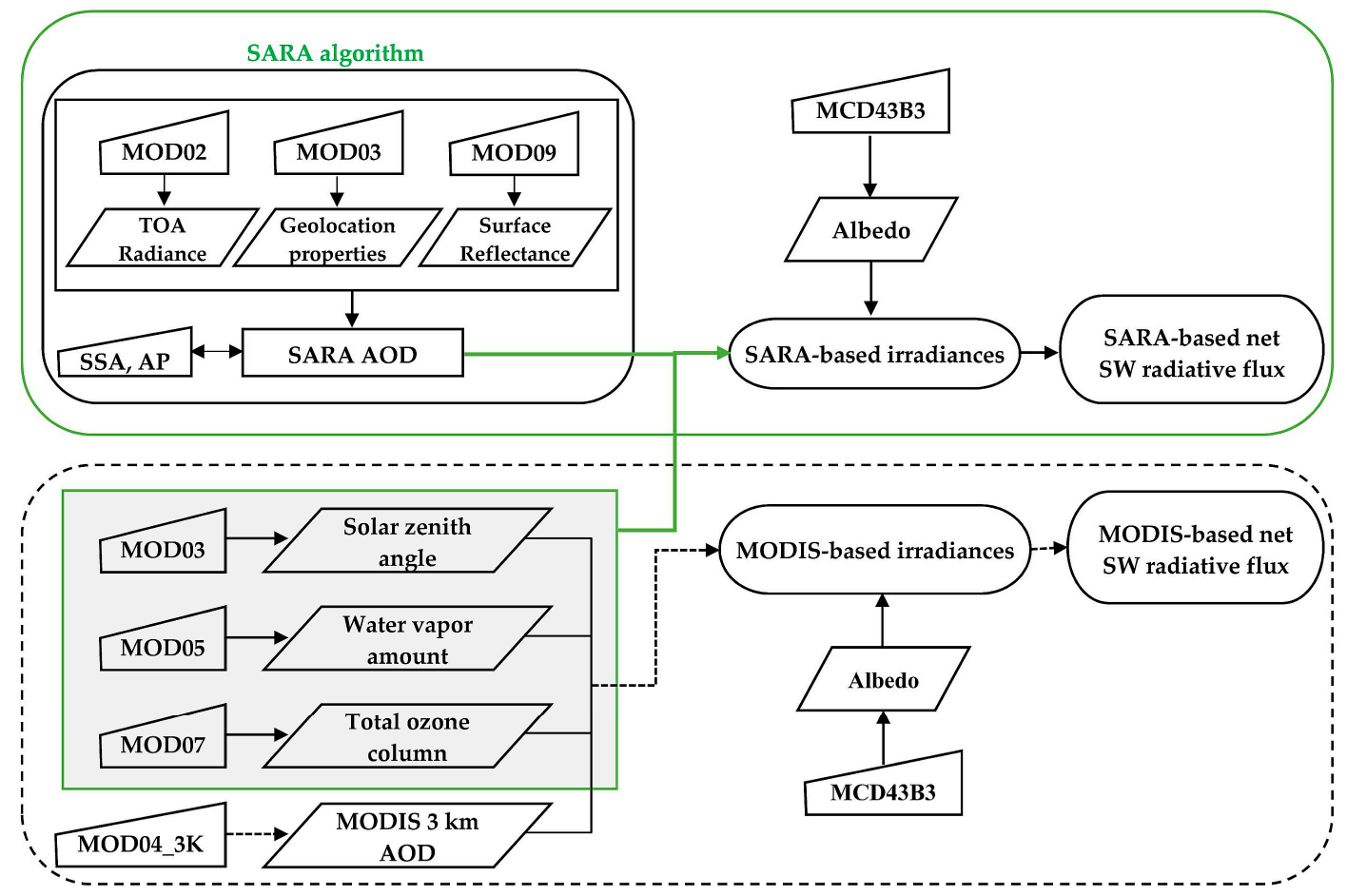

Figure 2. Framework showing the schemes of SARA- and MODIS-based shortwave (SW) radiative fluxes. The shaded area indicates the computation of transmittance factors shared by both schemes.

\section{Results}

\subsection{Comparison between $S A R A$ and MODIS AOD}

Figure 3 shows scatter plots of SARA 1-km AOD and MODIS 3-km AOD, respectively, and Multi-filter Rotating Shadowband Radiometer (MFRSR) AOD at the four ARM SGP sites. These sites are Ashton in Kansas (E9), Maple City in Kansas (E34), Tryon in Oklahoma (E35), and Omega in Oklahoma (E38). The SARA 1-km AOD obtained a high coefficient of determination $\left(\mathrm{R}^{2}=0.721\right)$ and low RMSE (0.032) and bias (0.010). Figure 3a reveals a close correspondence between the SARA AOD and MFRSR AOD, and the majority of the observations lie close to the 1:1 line, which indicates a good quality of the retrieved AOD. A relatively good agreement was also obtained for MODIS 3-km AOD and MFRSR AOD $\left(R^{2}=0.332, \mathrm{RMSE}=0.074\right.$, and bias $\left.=-0.040\right)$ (Figure 3b). However, MODIS AOD has approximately two times larger RMSE and four times larger bias than the SARA AOD. Figure $3 b$ for MODIS AOD shows a slope lower than unity and indicates a systematic underestimation. The MODIS aerosol retrieval algorithm underestimates AOD at dark surfaces that have a normalized difference vegetation index (NDVI) larger than 0.6. Average windows of $3 \mathrm{~km} \times 3 \mathrm{~km}$ pixels over the sites were calculated and show that the surroundings consist of dark surfaces (NDVI approaching 0.67) 
which should generate underestimated AOD values. These comparisons imply that SARA has as good or better ability to retrieve AOD.

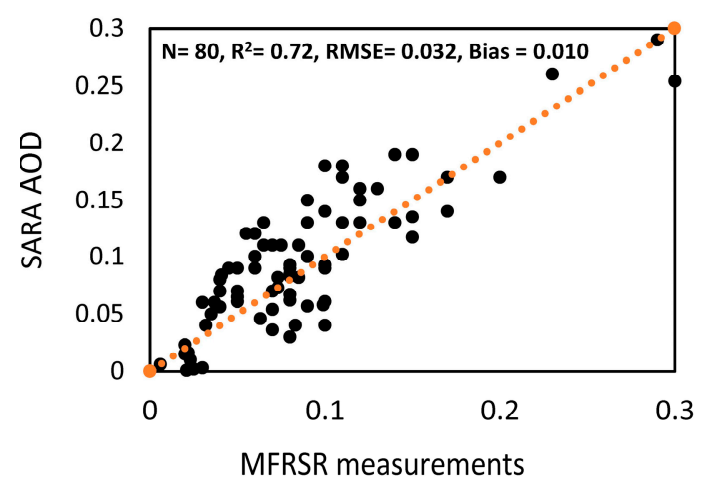

(a)

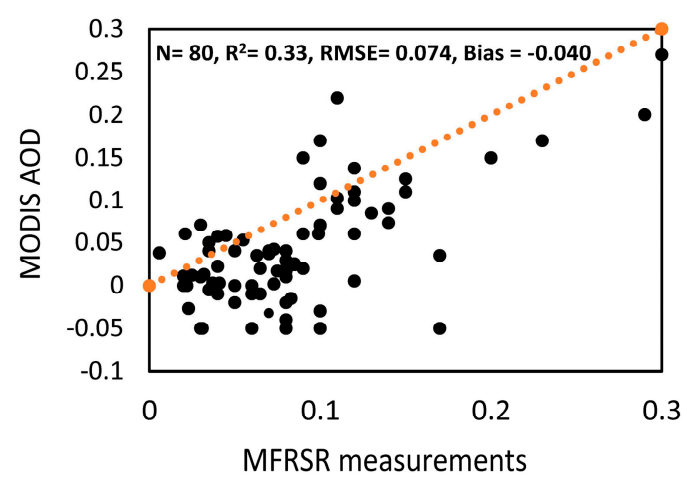

(b)

Figure 3. Scatterplots of SARA 1-km AOD (a) and MODIS 3-km AOD (b), respectively, and the Multi-filter Rotating Shadowband Radiometer (MFRSR) AOD at the ARM SGP sites.

\subsection{Validation of Downward SW Radiative Fluxes}

As previously mentioned, the modelling schemes were applied to twenty-six cloud-free days during January-November 2014. Estimated downward SW radiative fluxes were validated with ground-based measurements at the 13 SGP sites. Figure 4 shows scatter plots between each of the estimated SARA- and MODIS-based fluxes and observed fluxes. The SARA-based scheme obtained better results than the MODIS-based scheme with lower biases and RMSEs, and higher $\mathrm{R}^{2}$ values, especially for direct irradiance, which is highly sensitive to AOD (Table 3). This higher accuracy can be explained by SARA that accounts for detailed land and atmospheric properties to retrieve the AOD. Despite the overall good performance of the SARA-based scheme, it underestimates diffuse irradiance over the SGP. This may be due to systematic errors in the PSP measurements caused by the response of the thermopile-type pyranometers that are widely used at the SGP sites [33]. The bias of the SARA-based global irradiance is close to the results found by Bisht et al. [46] while our RMSE is lower, when they compared estimated global irradiance using the BB10 methodology over the SGP. The MODIS-based estimation of global irradiance is reasonable while the direct and diffuse components have large errors. This can be explained by the MODIS DT aerosol retrieval algorithm that underestimates AOD over dark surfaces. As shown in Figure 4, the MODIS-based scheme overestimates global and direct irradiances and underestimates diffuse irradiance. This is due to the opposite effect of AOD on the global and direct irradiances and diffuse irradiance; a decrease of AOD enhances global and direct irradiances and simultaneously reduces diffuse irradiance. The MODIS-based results of global irradiance are similar to those reported by Roupioz et al. [47] from the Qomolangma station where they validated the estimated MODIS-based global irradiance using the Yang et al. [25] model by integrating MODIS data and a digital elevation model (DEM) over the Tibetan Plateau.

The validation results show that the accuracy is improved by applying SARA AOD for downward SW radiative fluxes. The effect of using accurate AOD data on global irradiance is relatively lower than on the direct and diffuse components, and SARA-based direct and diffuse irradiances are two times more accurate than MODIS-based irradiances (1.5 times for global irradiance). Generally, in addition to the error induced by the interpolation of ground observations, the assumptions of SARA, various spatial resolutions of MODIS data products and the uncertainties of the MODIS land and atmospheric products can all contribute to the errors of the estimated SW radiative fluxes (see Section 4). 
SARA-based
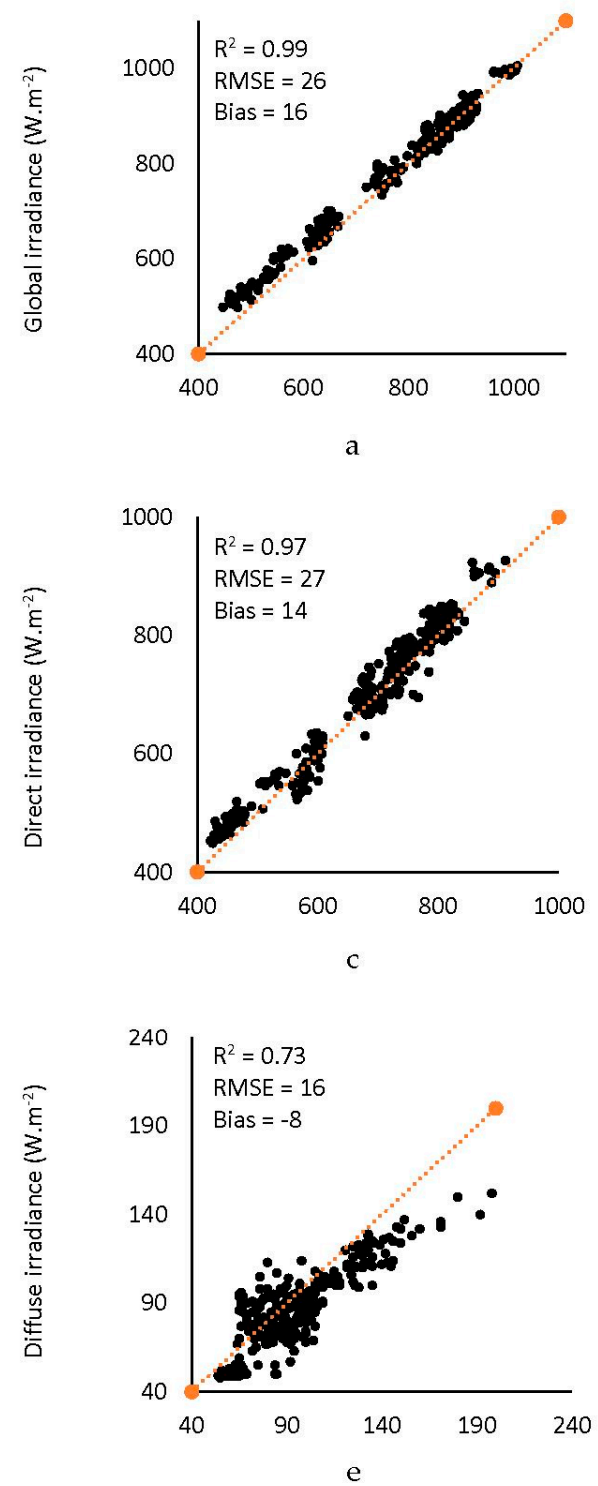

MODIS-based
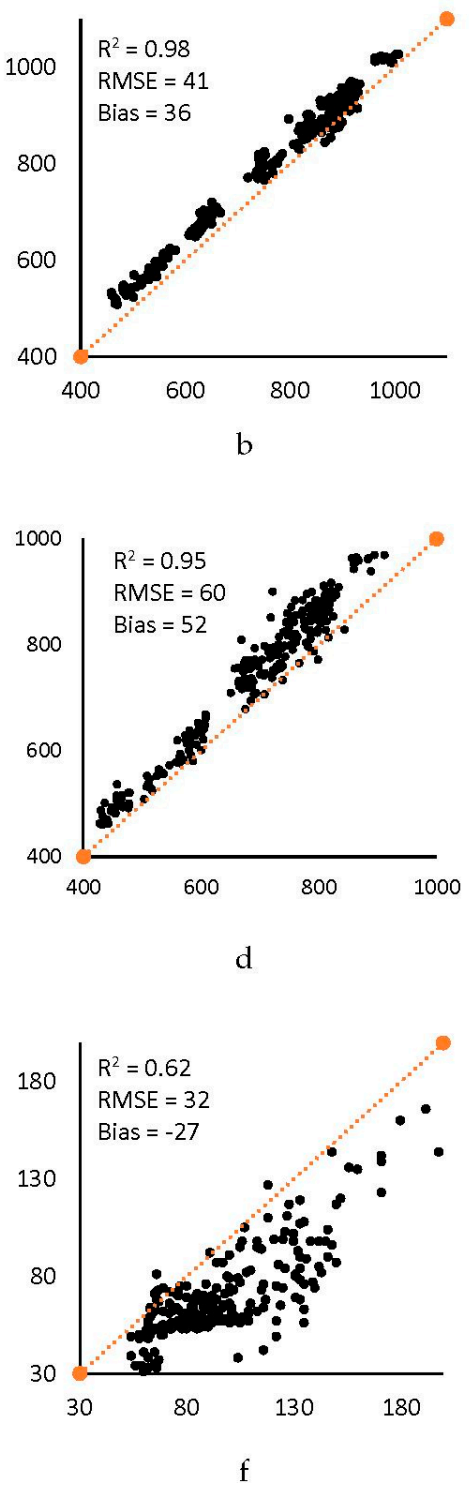

Observed SW irradiance (W. $\mathrm{m}^{-2}$ )

Figure 4. Scatterplots showing the relationships between each of the SARA-based (left) and MODIS-based (right) global $(\mathbf{a}, \mathbf{b})$, direct $(\mathbf{c}, \mathbf{d})$, and diffuse $(\mathbf{e}, \mathbf{f})$ shortwave (SW) irradiances and observed irradiance at the SGP sites in 2014.

Table 3. Validation statistics for the SARA- and MODIS-based global, direct, and diffuse shortwave (SW) irradiances at SGP sites in $2014^{\mathrm{a}}$.

\begin{tabular}{|c|c|c|c|c|}
\hline Scheme & Irradiances & $R^{2}$ & $\operatorname{RMSE}\left(\mathrm{W} \cdot \mathrm{m}^{-2}\right)$ & $\operatorname{Bias}\left(W \cdot m^{-2}\right)$ \\
\hline \multirow{3}{*}{ SARA-based } & Global & 0.99 & $26(3.4 \%)$ & 16 \\
\hline & Direct & 0.97 & $27(4 \%)$ & 14 \\
\hline & Diffuse & 0.73 & $16(17 \%)$ & -8 \\
\hline \multirow{3}{*}{ MODIS-based } & Global & 0.98 & $41(5.4 \%)$ & 36 \\
\hline & Direct & 0.95 & $60(8.8 \%)$ & 52 \\
\hline & Diffuse & 0.62 & $32(34 \%)$ & -27 \\
\hline
\end{tabular}

a The mean of observations for global, direct, and diffuse SW irradiances are $762 \mathrm{~W} \cdot \mathrm{m}^{-2}, 679 \mathrm{~W} \cdot \mathrm{m}^{-2}$, and $93 \mathrm{~W} \cdot \mathrm{m}^{-2}$, respectively. 


\subsection{Validation of Net Surface SW Radiative Fluxes}

In order to further evaluate the effectiveness of the SARA-based scheme, both SARA- and MODIS-based net surface SW radiative fluxes were validated with ground-based measurements at the 13 SGP sites. Figure 5 shows that the SARA-based net fluxes are similar to the MODIS-based net fluxes, and that both schemes slightly overestimate net fluxes. Table 4 shows that even if better results are obtained with SARA AOD than with MODIS 3-km AOD, the differences are small. Global irradiance and surface albedo are the two main controlling factors of net fluxes, and since MODIS albedo is used in both schemes, estimated fluxes are affected in the same way between the schemes. Although MODIS AOD produces somewhat larger RMSE and bias errors than SARA AOD, both schemes could provide the required accuracy for estimation of net SW fluxes.

Table 4. Validation statistics for the SARA- and MODIS-based net surface SW radiative fluxes at the SGP sites in $2014^{\mathrm{a}}$.

\begin{tabular}{cccc}
\hline Net SW Flux & $\mathbf{R}^{\mathbf{2}}$ & RMSE $\left(\mathbf{W} \cdot \mathbf{m}^{-\mathbf{2}}\right)$ & Bias $\left(\mathbf{W} \cdot \mathbf{m}^{-\mathbf{2}} \mathbf{)}\right.$ \\
\hline SARA-based & 0.97 & $36(5.9 \%)$ & $26(4.2 \%)$ \\
MODIS-based & 0.97 & $47(7.5 \%)$ & $41(6.5 \%)$ \\
\hline
\end{tabular}

a The mean of observations for net SW radiative fluxes is $620 \mathrm{~W} \cdot \mathrm{m}^{-2}$.

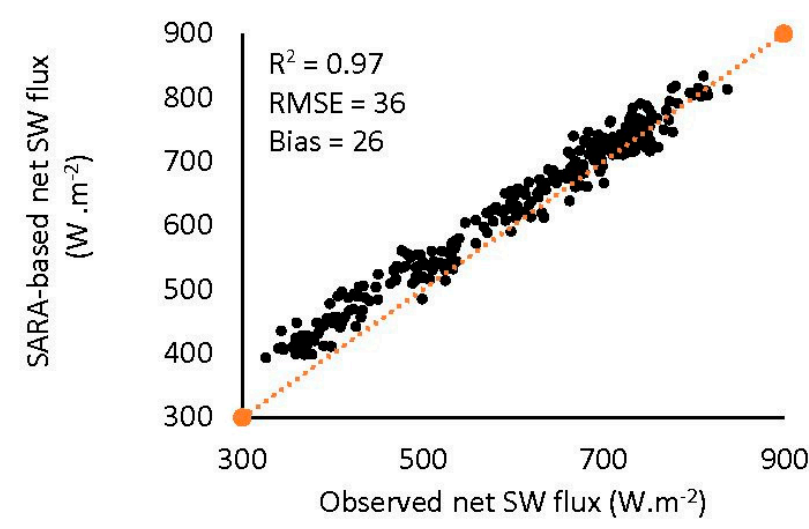

a

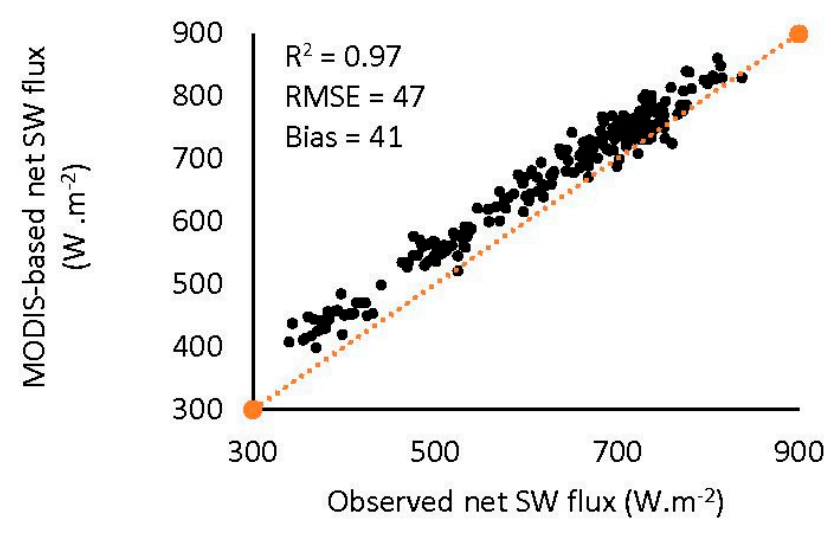

b

Figure 5. Scatterplots showing the relationships between each of SARA-based (a) and MODIS-based (b) net SW radiative fluxes and observed fluxes at the SGP sites in 2014. 


\subsection{Spatial Representations of Estimated Global Irradiance}

Figure $6 \mathrm{a}, \mathrm{b}$ show spatial representations of SARA- and MODIS-based global irradiance over the SGP on 20 July 2014. It is clear form these visualizations that higher resolution AOD is required to represent the landscape heterogeneity; 1-km SARA AOD is used as an input to the computation of the SARA-based irradiance (Figure 6c) while the 3-km MODIS AOD is used as an input to the computation of the MODIS-based irradiance (Figure 6d). Obviously, the SARA-based scheme captures spatial variations much better than the MODIS-based scheme. Not only are the SARA-based estimates in better agreement with ground-based measurements, but they also better represent spatial variations throughout the landscape.

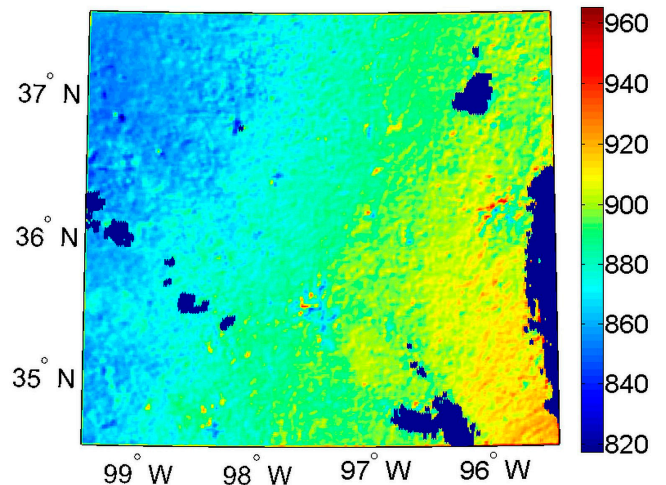

(a)

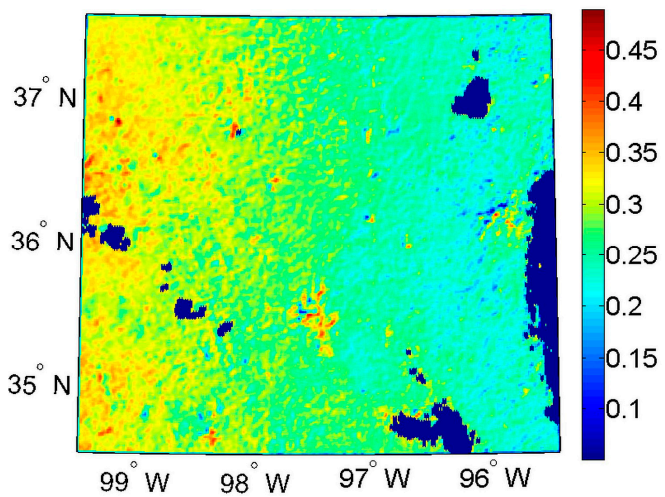

(c)

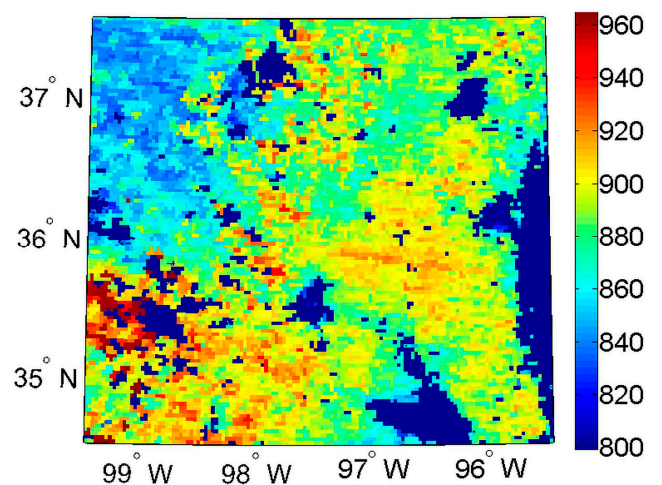

(b)

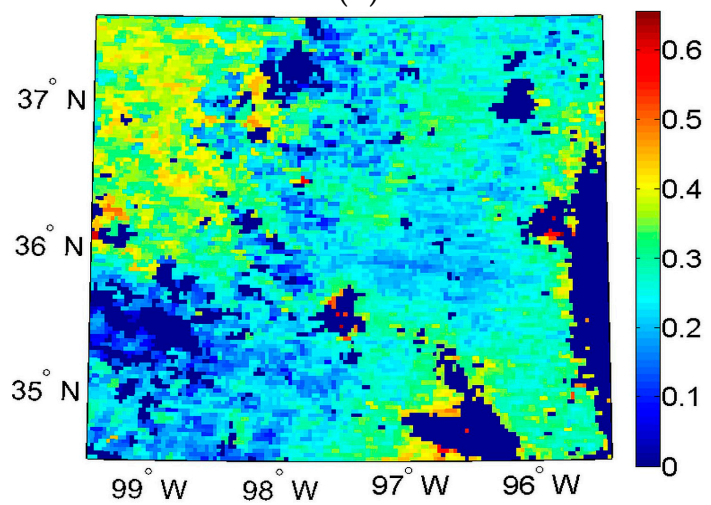

(d)

Figure 6. Spatial pattern of estimated (a) SARA-based global irradiance and (b) MODIS-based global irradiance using (c) 1-km SARA AOD and (d) 3-km MODIS AOD on 20 July 2014 over the SGP. In the left maps, the violet color represents no information because of cloud cover and in the right maps no information because of both cloud cover and missing values in the MODIS product.

\subsection{Comparison with Other Studies}

The comparison of the SARA-based estimations provided by our hybrid approach with other studies is based on the results from three papers: Bisht and Bras [46], Roupioz et al. [47], and Rutan et al. [48].

Bisht and Bras [34] estimated SW radiative fluxes with the BB10 methodology over the SGP under cloud-free conditions in 2006. They validated estimated fluxes with ground-based measurements at 21 stations and reported RMSEs of $42 \mathrm{~W} \cdot \mathrm{m}^{-2}$ and $39 \mathrm{~W} \cdot \mathrm{m}^{-2}$ and biases of $18 \mathrm{~W} \cdot \mathrm{m}^{-2}$ and $23 \mathrm{~W} \cdot \mathrm{m}^{-2}$ for global irradiance and net flux, respectively. Their results are close to our findings although the RMSE of our SARA-based global irradiance is $16 \mathrm{~W} \cdot \mathrm{m}^{-2}$ lower.

Roupioz et al. [37] used Yang's et al. [25] model together with MODIS land and atmospheric products, including the MODIS standard AOD product, and a DEM to account for the topography 
of the rugged Tibetan Plateau. They validated MODIS-based global irradiance and net flux with ground-based measurements at the Qomolangma station under cloud-free conditions in 2009. For global irradiance and net flux, respectively, they reported RMSEs of $49 \mathrm{~W} \cdot \mathrm{m}^{-2}$ and $44 \mathrm{~W} \cdot \mathrm{m}^{-2}$, biases of $11 \mathrm{~W} \cdot \mathrm{m}^{-2}$ and $23 \mathrm{~W} \cdot \mathrm{m}^{-2}$, and $\mathrm{R}^{2}$ values of 0.89 and 0.73 . Their net flux results are comparable to our findings while the RMSE of our SARA-based global irradiance is half as large.

Rutan et al. [38] validated the CERES/SARB data product with ground-based measurements at 20 stations over the SGP under cloud-free conditions in 2001. They obtained a RMSE of $18 \mathrm{~W} \cdot \mathrm{m}^{-2}$ and a bias of $3 \mathrm{~W} \cdot \mathrm{m}^{-2}$ for the global irradiance product. Their RMSE is comparable to our result while their bias is better.

\section{Discussion}

The validation showed that better retrieval was obtained using the SARA-based modeling scheme for downward surface SW fluxes, and especially for direct irradiance. However, the validations of both schemes were affected by the temporal difference between the MODIS overpass time, which is the time used in the computation, and the 15-min average ground observations.

There are several sources of error to be discussed. One is the identification of cloud-free days that was based on MODIS LST. A simple test was conducted by identifying cloudy conditions based on the difference between the ground measurements and the TOA irradiance. The results showed that identified days using this method differed from the ones identified with MODIS LST (which is based on the MODIS cloud fraction product). This discrepancy can affect the estimation of fluxes, particularly diffuse irradiance under cloud-free conditions.

The uncertainties of the MODIS-derived land and atmospheric parameters influence the accuracy of estimated fluxes. Inconsistencies between MODIS-based estimates and SGP observations are probably related to uncertainties in the retrieval of MODIS AOD. Not only is the spatial resolution coarse, but the MODIS DT aerosol retrieval algorithm is sensitive to land surface characteristics, and according to results from Levy et al. [20], the MODIS DT algorithm underestimates AOD by 0.02 or more at sites with a NDVI larger than 0.6. Therefore, the relatively large errors of MODIS-based fluxes over the study area may be attributed to dark land surfaces over the SGP.

The main limitations of our hybrid scheme are the assumptions of a constant single scattering albedo and asymmetry factor over the study area and that retrieval of surface SW fluxes is restricted to cloud-free conditions. Single scattering albedo and asymmetry factors are retrieved using SARA and AOD from the CART AERONET site, and are assumed to be constant over the entire study area on the day of retrieval. This assumption may not be valid for all SGP sites, for example, E21 and E36 are approximately $170 \mathrm{~km}$ and $100 \mathrm{~km}$ away from the retrieval site, respectively. For our scheme to be applicable at regional to global scales, we need more AREONET sites to account for the spatial variability of the single scattering albedo and asymmetry factor. To account for cloudy conditions and the effects of clouds on surface SW fluxes, our scheme could be improved in the future by incorporating cloud data from MODIS and the cloud transmittance scheme described by Stephens et al. [40].

The validation also showed that estimated net surface SW radiative fluxes are less accurate than estimated downward irradiances and that the difference between the SARA- and MODIS-based schemes is smaller. Even if this lower accuracy is mainly due to uncertainties in MODIS albedo, it may also be caused by spatial and temporal mismatches between satellite- and ground-based observations; the schemes use the eight-day MODIS albedo, and if the vegetation cover changes during an eight-day period, then changes in albedo introduce errors in net flux estimates.

Overall, the SARA-based estimates agree better with ground-based observations than MODIS-based estimates, as well as with earlier studies such as Bisht and Bras [37] and Roupioz et al. [38]. Another advantage of the proposed hybrid scheme is its capability to retrieve high-resolution SW radiative fluxes over all types of surfaces, including bright and dark surfaces under clear and turbid atmospheric conditions. Therefore, our SARA-based hybrid scheme is suitable for driving land surface models such as GEWEX [41] and CCSM [42] to better predict land surface 
processes, under the likely assumption of future access to all-sky radiative fluxes. High-resolution flux data can also bridge the gap between existing coarse-resolution products and point-based field measurements and be used to validate coarse-resolution data.

\section{Conclusions}

This study estimated surface SW radiative fluxes for all cloud-free days over the study area within the SGP in 2014 and successfully evaluated the estimated fluxes with ground-based pyranometer measurements at 13 sites. Using radiative transmittance factors from Yang et al.'s [25] model, fluxes were estimated in two ways: firstly, by applying the SARA-based scheme, namely based on AOD retrieved from SARA and ground-based measurements at the CART AERONET site, and secondly, by applying the MODIS-based scheme, namely based on the new Terra MODIS 3-km AOD. Several other Terra MODIS land and atmospheric products were also used as an input to both schemes, including geolocation properties, water vapor amount, total ozone column, surface reflectance, and TOA radiance. The validation results show higher accuracy for the SARA-based scheme compared to the MODIS-based scheme, especially for direct and diffuse irradiances, where SARA-based direct and diffuse irradiances are about two times more accurate. This relatively large difference between the schemes is mainly due to the different aerosol data used. Not only the coarse resolution of MODIS AOD, but primarily the MODIS DT algorithm induces errors in the estimated fluxes. It should be noted that the SARA-based scheme obtained smaller or similar RMSE for global irradiance, also compared to other studies by Bisht and Bras [46], Roupioz et al. [47], and Rutan et al. [38]. Another advantage of the SARA-based scheme, as compared to the MODIS-based scheme and the CERES/SARB data product [38], is that it produces higher-resolution fluxes that are necessary to represent spatial variability throughout a landscape. However, a future development of the SARA-based scheme is needed to account for cloudy conditions by incorporating MODIS cloud data and the scheme for cloud transmittance described by Stephens et al. [40]. The schemes were also used to estimate net SW radiative fluxes. However, for both schemes, validation showed lower accuracies compared to global irradiance and its direct and diffuse components. This is mainly due to uncertainties in the coarse resolution MODIS albedo and, therefore, estimation of net fluxes should be improved by using higher temporal resolution albedo products.

The main purpose of our proposed hybrid approach is to provide estimation possibilities for higher-resolution surface SW radiative fluxes to be used at the regional to global scales. However, such regional to global applications require a spatially distributed network of AERONET sites. Using only one AERONET site leads to errors in the computation. However, under the likely assumption of future access to a larger network, our study results show that our hybrid scheme enables estimations of fluxes for modeling and planning purposes in various areas, such as solar energy applications and land and climate models at the regional to global scales.

Acknowledgments: The MODIS data were obtained from the NASA Goddard Space Flight Center, the AOD data from the AErosol RObotic NETwork (AERONET), and solar flux data from the U.S. Department of Energy (DOE).

Author Contributions: Eslam Javadnia and Ali Akbar Abkar conceived and designed the study. Eslam Javadania performed the research including preparing and processed the data. Eslam Javadnia, Ali Akbar Abkar, and Per Schubert analyzed the processed data. Eslam Javadnia and Per Schubert wrote the paper, assisted by Ali Akbar Abkar. All authors discussed the results and implications and commented on the manuscript at all stages.

Conflicts of Interest: The authors declare no conflict of interest.

\section{Abbreviations}

The following abbreviations are used in this manuscript:

$\begin{array}{ll}\text { AERONET } & \text { AErosol RObotic NETwork } \\ \text { AOD } & \text { Aerosol Optical Depth } \\ \text { AP } & \text { Asymmetry parameter } \\ \text { ARM } & \text { Atmospheric Radiation Measurement }\end{array}$




$\begin{array}{ll}\text { DB } & \text { Deep Blue } \\ \text { DEM } & \text { Digital elevation model } \\ \text { DT } & \text { Dark Target } \\ \text { EF } & \text { Extended facility } \\ \text { LST } & \text { Land Surface Temperature } \\ \text { MFRSR } & \text { Multi-filter Rotating Shadowband adiometer } \\ \text { MODIS } & \text { MODerate resolution Imaging Spectroradiometer } \\ \text { NDVI } & \text { normalized difference vegetation index } \\ \text { NIP } & \text { Normal Incidence Pyrheliometer } \\ \text { NSSR } & \text { Net Surface Shortwave Radiation } \\ \text { PSP } & \text { Precision Spectral Pyranometers } \\ \text { SARA } & \text { Simplified Aerosol Retrieval Algorithm } \\ \text { SGP } & \text { Southern Great Plains } \\ \text { SIRS } & \text { Solar Infrared Radiation Stations } \\ \text { SSA } & \text { Single scattering albedo } \\ \text { SW } & \text { Shortwave } \\ \text { TOA } & \text { Top of Atmosphere }\end{array}$

\section{References}

1. Solomon, S.; Qin, D.; Manning, M.; Marquis, M.; Averyt, K.; Tignor, M.; Miller, H.; Chen, Z. Climate Change 2007: The Physical Science Basis; Cambrige University Press: New York, NY, USA, 2007.

2. Sellers, P.; Dickinson, R.; Randall, D.; Betts, A.; Hall, F.; Berry, J.; Collatz, G.; Denning, A.; Mooney, H.; Nobre, C.; et al. Modeling the exchanges of energy, water, and carbon between continents and the atmosphere. Science 1997, 275, 502-509. [CrossRef] [PubMed]

3. Jiang, L.; Islam, S.; Guo, W.; Jutla, A.S.; Senarath, S.U.; Ramsay, B.H.; Eltahir, E. A satellite-based daily actual evapotranspiration estimation algorithm over south florida. Glob. Planet. Chang. 2009, 67, 62-77. [CrossRef]

4. Carrer, D.; Lafont, S.; Roujean, J.-L.; Calvet, J.-C.; Meurey, C.; Le Moigne, P.; Trigo, I. Incoming solar and infrared radiation derived from meteosat: Impact on the modeled land water and energy budget over france. J. Hydrometeorol. 2012, 13, 504-520. [CrossRef]

5. Jia, L.; Roupioz, L.; Hu, G.; Zhou, J. Anomalies Maps of Net Radiation, LST and FPAR; CEOP-AEGIS Deliverable Report De9. 7; University of Strasbourg: Strasbourg, France, 2011.

6. Kim, H.-Y.; Liang, S. Development of a hybrid method for estimating land surface shortwave net radiation from MODIS data. Remote Sens. Environ. 2010, 114, 2393-2402. [CrossRef]

7. Li, Z.; Leighton, H.; Cess, R.D. Surface net solar radiation estimated from satellite measurements: Comparisons with tower observations. J. Clim. 1993, 6, 1764-1772. [CrossRef]

8. Li, Z.; Leighton, H.; Masuda, K.; Takashima, T. Estimation of sw flux absorbed at the surface from TOA reflected flux. J. Clim. 1993, 6, 317-330. [CrossRef]

9. Tang, B.; Li, Z.-L.; Zhang, R. A direct method for estimating net surface shortwave radiation from MODIS data. Remote Sens. Environ. 2006, 103, 115-126. [CrossRef]

10. Niu, X.; Pinker, R.T. An improved methodology for deriving high-resolution surface shortwave radiative fluxes from modis in the arctic region. J. Geophys. Res. Atmos. 2015, 120, 2382-2393. [CrossRef]

11. Chen, M.; Zhuang, Q.; He, Y. An efficient method of estimating downward solar radiation based on the MODIS observations for the use of land surface modeling. Remote Sens. 2014, 6, 7136-7157. [CrossRef]

12. Lu, N.; Qin, J.; Yang, K.; Sun, J. A simple and efficient algorithm to estimate daily global solar radiation from geostationary satellite data. Energy 2011, 36, 3179-3188. [CrossRef]

13. Pinker, R.; Laszlo, I. Modeling surface solar irradiance for satellite applications on a global scale. J. Appl. Meteorol. 1992, 31, 194-211. [CrossRef]

14. Tang, W.; Qin, J.; Yang, K.; Niu, X.; Min, M.; Liang, S. An efficient algorithm for calculating photosynthetically active radiation with modis products. Remote Sens. Environ. 2017, 194, 146-154. [CrossRef]

15. Tang, W.; Qin, J.; Yang, K.; Liu, S.; Lu, N.; Niu, X. Retrieving high-resolution surface solar radiation with cloud parameters derived by combining MODIS and MTSAT data. Atmos. Chem. Phys. 2016, 16, 2543-2557. [CrossRef] 
16. Tang, W.; Yang, K.; Sun, Z.; Qin, J.; Niu, X. Global performance of a fast parameterization scheme for estimating surface solar radiation from MODIS data. IEEE Trans. Geosci. Remote Sens. 2017, 55, 3558-3571. [CrossRef]

17. Huang, G.; Ma, M.; Liang, S.; Liu, S.; Li, X. A LUT-based approach to estimate surface solar irradiance by combining MODIS and MTSAT data. J. Geophys. Res. Atmos. 2011, 116, D22201. [CrossRef]

18. Pinker, R.T.; Tarpley, J.D.; Laszlo, I.; Mitchell, K.E.; Houser, P.R.; Wood, E.F.; Schaake, J.C.; Robock, A.; Lohmann, D.; Cosgrove, B.A.; et al. Surface radiation budgets in support of the GEWEX Continental-Scale International Project (GCIP) and the GEWEX Americas Prediction Project (GAPP), including the north american land data assimilation system (NLDAS) project: GewexCcontinental-Scale International Project, part 3 (GCIP3). J. Geophys. Res. 2003, 108. [CrossRef]

19. Suri, M.; Remund, J.; Cebecauer, T.; Hoyer-Click, C.; Dumortier, D.; Huld, T.; Stackhouse, P.; Ineichen, P. Comparison of direct normal irradiation maps for Europe. In Proceedings of the Solar PACES Conference, Berlin, Germany, 15-18 September 2009.

20. Gueymard, C.A. Temporal variability in direct and global irradiance at various time scales as affected by aerosols. Solar Resour. 2012, 86, 3544-3553. [CrossRef]

21. Gueymard, C.A. Uncertainties in modeled direct irradiance around the sahara as affected by aerosols: Are current datasets of bankable quality? J. Sol. Energy Eng. 2011, 133, 031024. [CrossRef]

22. Castelli, M.; Stöckli, R.; Zardi, D.; Tetzlaff, A.; Wagner, J.E.; Belluardo, G.; Zebisch, M.; Petitta, M. The Heliomont method for assessing solar irradiance over complex terrain: Validation and improvements. Remote Sens. Environ. 2014, 152, 603-613. [CrossRef]

23. Hubanks, P.; King, M.; Platnick, S.; Pincus, R. MODIS Atmosphere L3 Gridded Product Algorithm Theoretical Basis Document; Collection 005 Version 1.1, Technical Report ATBT-MOD-30; NASA: Greenbelt, MD, USA, 2008.

24. Li, F.; Kustas, W.P.; Anderson, M.C.; Prueger, J.H.; Scott, R.L. Effect of remote sensing spatial resolution on interpreting tower-based flux observations. Remote Sens. Environ. 2008, 112, 337-349. [CrossRef]

25. Kustas, W.P.; Li, F.; Jackson, T.J.; Prueger, J.H.; MacPherson, J.I.; Wolde, M. Effects of remote sensing pixel resolution on modeled energy flux variability of croplands in iowa. Remote Sens. Environ. 2004, 92, 535-547. [CrossRef]

26. Bromwich, D.H.; Bai, L.; Bjarnason, G.G. High-resolution regional climate simulations over iceland using polar mm5. Mon. Weather Rev. 2005, 133, 3527-3547. [CrossRef]

27. Levy, R.; Remer, L.; Kleidman, R.; Mattoo, S.; Ichoku, C.; Kahn, R.; Eck, T. Global evaluation of the collection 5 MODIS dark-target aerosol products over land. Atmos. Chem. Phys. 2010, 10, 10399-10420. [CrossRef]

28. Levy, R.C.; Remer, L.A.; Mattoo, S.; Vermote, E.F.; Kaufman, Y.J. Second-generation operational algorithm: Retrieval of aerosol properties over land from inversion of moderate resolution imaging spectroradiometer spectral reflectance. J. Geophys. Res. Atmos. 2007, 112, D13211. [CrossRef]

29. Hsu, N.C.; Tsay, S.-C.; King, M.D.; Herman, J.R. Deep blue retrievals of Asian aerosol properties during ACE-Asia. IEEE Trans. Geosci. Remote Sens. 2006, 44, 3180-3195. [CrossRef]

30. Remer, L.; Mattoo, S.; Levy, R.; Munchak, L. MODIS 3 km aerosol product: Algorithm and global perspective. Atmos. Meas. Tech. 2013, 6, 1829-1844. [CrossRef]

31. Bilal, M.; Nichol, J.E.; Bleiweiss, M.P.; Dubois, D. A simplified high resolution MODIS Aerosol Retrieval Algorithm (SARA) for use over mixed surfaces. Remote Sens. Environ. 2013, 136, 135-145. [CrossRef]

32. Yang, K.; Koike, T.; Huang, G.; Tamai, N. Development and validation of an advanced model for estimating solar radiation from surface meteorological data. In Recent Developments in Solar Energy; Hough, T.P., Ed.; Nova Science Publishers: Hauppauge, NY, USA, 2007; pp. 1-53.

33. Stoffel, T. Solar and Infrared Radiation Station (SIRS) Handbook; PNNL: Richland, WA, USA; DOE Office of Science Atmospheric Radiation Measurement (ARM) Program (United States): Richland, WA, USA, 2005.

34. Atmospheric Radiation Measurement (ARM) Web Site. Available online: http://www.arm.gov/ (accessed on 25 October 2017).

35. IIqbal, M. Total (broadband) radiation under cloudless skies. In An Introduction to Solar Radiation, 1st ed.; Academic Press: New York, NY, USA, 1983; pp. 169-213.

36. Yang, K.; Huang, G.; Tamai, N. A hybrid model for estimating global solar radiation. Sol. Energy 2001, 70, 13-22. [CrossRef]

37. Gueymard, C.A. Direct solar transmittance and irradiance predictions with broadband models. Part I: Detailed theoretical performance assessment. Sol. Energy 2003, 74, 355-379. [CrossRef] 
38. Gueymard, C.A. Direct solar transmittance and irradiance predictions with broadband models. Part II: Validation with high-quality measurements. Sol. Energy 2003, 74, 381-395. [CrossRef]

39. Madkour, M.; El-Metwally, M.; Hamed, A. Comparative study on different models for estimation of Direct Normal Irradiance (DNI) over Egypt atmosphere. Renew. Energy 2006, 31, 361-382. [CrossRef]

40. Moody, E.G.; King, M.D.; Platnick, S.; Schaaf, C.B.; Gao, F. Spatially complete global spectral surface albedos: Value-added datasets derived from Terra MODIS land products. IEEE Trans. Geosci. Remote Sens. 2005, 43, 144-158. [CrossRef]

41. Bilal, M.; Nichol, J.E. Evaluation of MODIS aerosol retrieval algorithms over the Beijing-Tianjin-Hebei region during low to very high pollution events. J. Geophys. Res. Atmos. 2015, 120, 7941-7957. [CrossRef]

42. Bilal, M.; Nichol, J.E.; Chan, P.W. Validation and accuracy assessment of a Simplified Aerosol Retrieval Algorithm (SARA) over Beijing under low and high aerosol loadings and dust storms. Remote Sens. Environ. 2014, 153, 50-60. [CrossRef]

43. Bilal, M.; Nazeer, M.; Nichol, J.E. Validation of MODIS and VIIRS derived aerosol optical depth over complex coastal waters. Atmos. Res. 2017, 186, 43-50. [CrossRef]

44. Ichoku, C.; Levy, R.; Kaufman, Y.J.; Remer, L.A.; Li, R.R.; Martins, V.J.; Holben, B.N.; Abuhassan, N.; Slutsker, I.; Eck, T.F. Analysis of the performance characteristics of the five-channel Microtops II Sun photometer for measuring aerosol optical thickness and precipitable water vapor. J. Geophys. Res. Atmos. 2002, 107, AAC 5-1-AAC 5-17. [CrossRef]

45. Leckner, B. The spectral distribution of solar radiation at the earth's surface-Elements of a model. Sol. Energy 1978, 20, 143-150. [CrossRef]

46. Bisht, G.; Bras, R.L. Estimation of net radiation from the MODIS data under all sky conditions: Southern Great Plains case study. Remote Sens. Environ. 2010, 114, 1522-1534. [CrossRef]

47. Roupioz, L.; Jia, L.; Nerry, F.; Menenti, M. Estimation of daily solar radiation budget at kilometer resolution over the Tibetan Plateau by integrating MODIS data products and a DEM. Remote Sens. 2016, 8, 504. [CrossRef]

48. Rutan, D.A.; Charlock, T.; Rose, F.; Manalo-Smith, N. Validation of CERES/SARB Data Product Using ARM Surface Flux Observations. In Proceedings of the 14th ARM Science Team Meeting, Albuquerque, New Mexico, 22-26 March 2004. 